\title{
Dificuldades e peculiaridades que interferem na gestão das empresas familiares dos municípios de Gramado e Canela - RS
}

\author{
Kelly Magnus ${ }^{\top}$ \\ Silvio Aurélio Jaeger ${ }^{2}$
}

\section{Resumo}

A delimitação do tema do estudo é a gestão das empresas familiares nas cidades de Gramado e Canela - RS. O problema de pesquisa é definido em quais são as dificuldades encontradas na gestão das empresas familiares nas referidas cidades. O objetivo geral do trabalho consiste na verificação e na análise das dificuldades que interferem na gestão das empresas familiares dessas duas cidades. $O$ estudo se justifica pela relevância do tema e pela importância de amenizar os problemas de gestão das empresas familiares, visando à continuidade e à perpetuação do negócio. A metodologia utilizada foi a pesquisa quantitativa, de caráter descritivo, por meio de levantamento através de um questionário aplicado a duas gerações de empresas familiares. A partir da análise dos dados, identificaram-se algumas das dificuldades enfrentadas pelas empresas familiares dos municípios analisados, como, por exemplo, a gestão é desestruturada, as atividades dos membros da família não são definidas, os conflitos ocorrem devido à interferência da relação família-empresa, as mudanças não são bem aceitas e a sucessão não é planejada.

Palavras-chave: Empresa familiar. Gestão familiar. Conflitos. Sucessão.

\section{Abstract}

The delimitation of the subject of the study is the management of family firms in the cities of Gramado and Canela-RS. The search problem is defined in, what are the difficulties encountered in the management of family firms in the cities of Gramado and Canela-RS. The overall objective of the work the verification and analysis of the difficulties that interfere in the management of family businesses of the two cities, already pointed out. The study is justified by the relevance of the topic and the importance of alleviating the problems of management of family businesses, aiming at continuity and perpetuation of the business. The methodology used was the quantitative research, descriptive character, through lifting, through a questionnaire applied to two generations of family businesses. From the analysis of the data collected identified some of the difficulties faced by family businesses municipalities analyzed as, for example, the management is flattened, the activities of the members of the family are not defined, conflicts occur due to the interference of the family

\footnotetext{
${ }^{1}$ Bacharelanda em Administração - Universidade de Caxias do Sul - UCS/RS. kellymag@hotmail.com

${ }^{2}$ Mestre em Qualidade Ambiental - Universidade FEEVALE - Novo Hamburgo/RS. sajaeger@ucs.br
} 
relationship and company, the changes are not well accepted, and the succession is not planned.

Keywords: Family-owned company. Family management. Conflicts. Succession.

\section{Introdução}

A base econômica mundial, frequentemente, é sustentada por empresas, as quais geram empregos, pagam salários a seus funcionários, pessoas que logicamente irão consumir, criando-se então um ciclo de satisfação de desejos e necessidades tanto pessoais como empresariais. Dentre tantas empresas existentes, essas são separadas e então divididas em grupos, conforme suas características e semelhanças. Entre os diferentes tipos de empresas, está a familiar, sendo a mais numerosa e a responsável por grande parte da movimentação e sustentação da economia mundial (OLIVEIRA, 1999).

No Brasil, a tendência é igual à do restante do mundo. Pesquisas mostram que cerca de $70 \%$ das empresas de todo o mundo são familiares. No país, estima-se também que mais de $50 \%$ do Produto Interno Bruto nacional é atribuído às empresas familiares (GARCIA, 2001; OLIVEIRA, 1999). Ligada a esses números, está a cultura, que, no Brasil, se caracteriza por ser um país colonizado por estrangeiros, imigrantes alemães, italianos, portugueses, japoneses, entre outros. Esses imigrantes se espalharam por todo o território brasileiro, empreendendo, na maioria dos casos, pela necessidade de sobrevivência e pela busca de melhores condições de vida.

A empresa familiar é bastante parecida com os demais tipos, no entanto possui particularidades inerentes a esse tipo de empresa, como a interferência de questões familiares nas empresariais e vice-versa; a cultura, os princípios e valores familiares são transferidos para a empresa e, consequentemente, refletirão na história de ambas. A pessoa física do fundador, em muitos casos, é confundida com a pessoa jurídica por muito tempo. Assim como a empresa familiar possui características próprias, esse tipo de empresa também possui problemas particulares, como a dificuldade de separação entre empresa e família, os conflitos 
de interesses são comuns, dificuldades no planejamento da sucessão, além de fatores que interferirão diretamente na gestão da empresa.

A empresa, de modo geral, através de seus donos, espera que seu negócio cresça e se desenvolva de forma que gere um resultado positivo, podendo, então, maximizar o retorno financeiro aos proprietários e acionistas. No entanto, para que esse objetivo seja alcançado, cada vez mais a atenção com relação à gestão das empresas precisa ser redobrada, pois é a partir desta que a empresa poderá planejar ações, executá-las, dirigi-las e controlá-las, de forma que a empresa como um todo permaneça viva e crescente no mercado, que cada vez mais se torna altamente competitivo.

Devido à importância que as empresas familiares têm em todo o mundo, assim como na região de Canela e Gramado - RS, por suas particularidades, peculiaridades e dificuldades, e também pela importância da gestão para as empresas, que o tema gestão das empresas familiares foi escolhido para ser estudado, tendo como objetivo geral verificar e analisar as dificuldades que interferem na gestão das empresas familiares das cidades citadas. Este artigo está estruturado em seções. Primeiramente será apresentado um referencial teórico sobre os assuntos abordados no artigo, que está especificado na seção 2 . Posteriormente, na seção 3 , é descrita a metodologia utilizada para desenvolvimento do estudo. Na seção 4, estão expostos os dados e suas respectivas análises, assim como os resultados obtidos a partir dessas análises. Por fim, na seção 5 , são descritas as considerações finais.

\section{Fundamentação teórica}

Nesta seção, apresenta-se um breve referencial teórico sobre o que é uma empresa familiar, a importância da gestão para esse tipo de empresa e também algumas peculiaridades e dificuldades que as empresas familiares enfrentam.

\subsection{Empresa familiar}

Apesar de não existirem números concretos, Bueno, Fernández e Sámchez (2007) afirmam que a base econômica de grande parte do mundo, incluindo o Brasil, 
são as empresas familiares, já que a maioria das empresas privadas podem ser consideradas familiares.

Para Lacombi (2004, p. 128), empresa é uma "organização jurídica, econômica e social, constituída para produzir e/ou comercializar bens e/ou serviços e que possui objetivos próprios [...] ligados por sistemas de informação e influenciados por um ambiente externo". Moraes (2001) complementa, afirmando que uma empresa é orientada para o lucro, assume riscos e é constituída por pessoas, que se relacionam e realizam tarefas de forma cooperativa, de maneira que os objetivos traçados sejam alcançados.

As empresas podem ser divididas em diferentes tipos, e o que determinará qual será seu grupo são as características comuns entre elas. Entre os tipos de empresas, está a empresa familiar. De forma simplificada, Bernhoeft (1991, p. 35), define empresa familiar como "aquela que tem sua origem e história vinculadas a uma família”. Para Bueno, Fernández e Sámchez (2007), a definição de empresa familiar está ligada a três características: propriedade e o controle; a direção; a intenção de continuidade da empresa. Passos, Bernhoeft e Teixeira (2006) definem, de forma enxuta, que a empresa familiar é um sistema constituído de três subsistemas: família, patrimônio e empresa.

Conforme Oliveira (1999), o início de uma empresa familiar está ligado à visão de negócio do fundador empreendedor com o auxílio de membros da família na realização do trabalho, assim como em muitos casos ligados também à sobreposição de valores e normas empresariais com valores e normas familiares. $O$ mesmo autor ainda acrescenta que, nesse início de atividade, o que prevalece é a visão do negócio, a força de vontade e a forma de condução da empresa, ficando, então, a administração, propriamente dita, para mais tarde.

A continuidade da empresa requer esforços intensos e contínuos para que, dessa forma, problemas e particularidades desse tipo de empresa possam ser superados ou amenizados, podendo permanecer por mais tempo no mercado. Oliveira (1999) ressalta também que a adaptação das empresas ao ambiente em que estão inseridas é um dos elementos que contribuirão para a sua continuidade. $O$ mesmo autor aponta ainda que, entre os motivos do término das empresas 
familiares estão a carência em inovação, a falta de um planejamento estratégico estruturado e também brigas, conflitos e a sucessão.

Para Maximiano (2011), a administração das empresas familiares é mais complexa que a dos demais tipos. Essa complexidade se estabelece a partir da dinâmica desse tipo de empresa, que envolve questões de ordem emocional, legal, patrimonial e empresarial, questões particulares e próprias de cada empresa e família, o que difere tais empresas uma das outras (PASSOS; BERNHOEFT; TEIXEIRA, 2006). Visto assim, por mais similares e previsíveis que as empresas familiares sejam, com características de formação e desenvolvimento parecidas, questões de cunho particular necessitarão de soluções particulares, feitas de forma única, adaptadas a realidade de cada empresa e família.

\subsection{Gestão das empresas familiares}

A gestão da empresa familiar, assim como em qualquer outro tipo ou tamanho de empresa, pode ser considerada como quesito fundamental para o andamento da organização, de forma que o modo como esta é conduzida refletirá diretamente no cumprimento dos objetivos, metas, crescimento e sucesso da empresa. Com relação à gestão das empresas familiares, Tondo (2008) evidencia que esta é uma adaptação dos conceitos genéricos da administração, especializados às empresas familiares, tendo também como conceitos fundamentais o planejamento, organização, direção e controle. Álvares (2003) enfatiza que a prática da gestão se faz necessária para a sobrevivência da empresa, pois sem ela a empresa e a família, enquanto proprietárias do negócio estarão em risco de continuidade. De acordo com Garcia (2001, p. 167), "o gestor é o que participa ativamente da gestão e para isso deve se preparar". O autor ainda complementa que, como normalmente acontece nas empresas familiares, quem gerencia é o proprietário e essa preparação frequentemente é deficitária, pois ele pode não ter uma formação completa, conduzindo o seu negócio com base em intuições, experiências e "achismos".

De acordo com Bornholdt (2005), a gestão da empresa familiar é baseada na ideologia e cultura da família, na visão e na missão da empresa, assim com nas crenças e valores que nortearão a conduta do gestor na condução da empresa e na 
administração dos conflitos. O mesmo autor ainda afirma que a gestão familiar possui algumas peculiaridades, por isso a condução desse tipo de negócio vai além da administração da família, sociedade e empresa, mas sim na relação destes com os aspectos financeiros, afetivos e processo sucessório. A relação desses aspectos e a alta complexidade é que proporcionam um desafio constante e permanente na gestão das empresas familiares.

Garcia (2001) observa que, com o passar do tempo e com o crescimento da empresa, a forma de gerir que era feita apenas pelas convicções do gestor proprietário não são mais suficientes, demonstrando um clima de desordem e falta de planejamento empresarial, pois este, em muitos casos, se concentra apenas no pensamento do dono, não sendo externado para o restante dos membros da empresa, que incluem os familiares e os não familiares. De encontro com esta ideia, Bueno, Fernández e Sámchez (2007) dizem que a transição do proprietário, da primeira geração, para os filhos, a segunda geração, seria uma forma de solucionar essas questões de desordem, já que a nova geração normalmente possui um perfil mais profissionalizado do que o de seus pais. No entanto, esses membros não possuem autonomia para realizar mudanças estratégicas e organizacionais, pois o proprietário é que concentra toda essa responsabilidade em sua pessoa. Por outro lado, Lodi (1989) complementa que os herdeiros, despreparados ou não vocacionados, quando instalados na administração, podem vir a cometer graves erros de gestão, colocando em risco a continuidade da empresa.

\subsection{Problemas enfrentados pelas empresas familiares}

Com relação aos problemas enfrentados pelas empresas familiares, os conflitos são os mais comuns e constantes, sendo presentes de alguma forma, mais intensa ou mais ponderada, em todas as empresas do tipo familiar. Álvares (2003, p. 25) define conflito como "o confronto de duas necessidades e interesses, conscientes ou não". Ainda observa que os conflitos prejudicam o funcionamento da empresa, assim como o seu crescimento. Bueno et al. (2007), porém, afirmam que os conflitos podem contribuir para o crescimento da empresa, mas, para isso, precisam ser amenizados e não escondidos. 
Bornholdt (2005) aponta outro complicador das empresas familiares, que é a resistência à mudança. Ressalta que a necessidade de mudança e de adaptação ao mercado está diretamente ligada à sobrevivência da empresa, por isso é considerada um desafio para as empresas familiares. Ao encontro dessa afirmação, Bezerra (2009) acrescenta que outro fator dificultoso para a gestão das empresas familiares é a falta de profissionalização.

De forma geral, pode-se dizer que todas as empresas familiares enfrentam riscos e dificuldades próprios desse tipo de empresa. Entre eles, Rios (2002) aponta a dificuldade em estabelecer funções, direitos e deveres para cada um dos membros, a inexistência de normas rígidas e de profissionais para contratação de membros da família, o desrespeito à hierarquia, a falta de critérios para a remuneração de familiares, impunidade em caso de infração às regras, ausência de normas para orientar a gestão, uso da estrutura empresarial para fins particulares e a interferência dos problemas familiares na empresa.

Álvares (2003) também aponta alguns aspectos problemáticos das empresas familiares, como as dificuldades técnicas, acesso a mercados de capital, ajuste do estilo de liderança ao momento que a empresa vem passando, confusão na organização da empresa. Garcia (2001) complementa com outras dificuldades enfrentadas pelos gestores na gestão da empresa familiar, que são: interferência emocional na condução do processo, o aumento de conflitos pela não administração em tempo hábil, conflito de interesse entre as partes, adiamento da sucessão, falta de compromisso dos membros da família com a continuidade da empresa, falta de identificação da família com o negócio, experiências negativas, vários candidatos à sucessão, falta de unidade no comando, dificuldade de comunicação, falta de profissionalismo.

Outra questão complicada, também abordada por Rios (2002), referente à relação entre familiares, é a dificuldade de uma discussão aberta sobre problemas e conflitos, assim como o encaminhamento da sucessão da empresa. 


\section{Metodologia de pesquisa}

A partir do levantamento teórico e definido o problema da pesquisa, fica estabelecido o objetivo geral deste estudo: a verificação e a análise das dificuldades que interferem na gestão das empresas familiares das cidades de Gramado e Canela - RS. A partir disso, estipularam-se os seguintes objetivos específicos: (a) analisar se os conflitos familiares interferem na gestão das empresas familiares; (b) verificar quais são os efeitos da interferência da nova geração na gestão da empresa familiar; (c) investigar por que a modernização e profissionalização da empresa familiar são barradas; (d) analisar se existe algum planejamento para a sucessão nas empresas familiares pesquisadas.

Para atender e responder a esses objetivos, a pesquisa utilizada foi a quantitativa, de caráter descritivo, por meio de levantamento. $O$ universo instituído para essa pesquisa foram empresas familiares das cidades de Gramado e Canela RS. Pela falta de dados quanto à quantidade de empresas familiares nas duas cidades pesquisadas, estipulou-se o universo da pesquisa em 1.294 mil empresas familiares. Isso porque, de acordo com informações obtidas junto a Agência da Receita Estadual de Gramado, das 3.316 mil empresas de Gramado e Canela inscritas junto a Receita Estadual, 2.791 mil empresas estão enquadradas no regime tributário do Simples Nacional, ou seja, $84,17 \%$ do total de empresas inscritas das duas cidades são consideradas micro ou empresa de pequeno porte. Tendo por base a pesquisa realizada pelo Instituto Brasileiro de Geografia e Estatística (IBGE), em 2003, a qual aponta quem, em 2001, 46,34\% das micro e pequenas empresas do Brasil eram empresas familiares, utilizou-se dessa mesma porcentagem para supor que, do total de 2.791 mil empresas das cidades em questão, enquadradas no Simples Nacional, $46,34 \%$ ou 1.294 mil delas podem ser consideradas familiares.

Quanto à amostra, estipulou-se que girará em torno de 278 empresas entrevistadas, tendo por base o universo de 1.294 mil empresas familiares, um nível de confiança de $95 \%$, um erro amostral de $5 \%$ e um split de 50/50.

Para coleta de dados, o instrumento utilizado para este estudo foi o questionário, de predominância de questões fechadas, de múltipla escolha, e 
apenas duas questões abertas. Foram aplicados em empresas familiares e respondidos por dois integrantes da família e da empresa, considerando-se que cada um deve pertencer a gerações diferentes, obtendo-se, então, dois questionários por empresa pesquisada. O primeiro contato com a empresa foi de forma presencial, quando se verificou se o respondente preferiria receber o questionário de forma física ou eletrônica. Se a forma desejada for física, o questionário será buscado pelo pesquisador posteriormente; se a forma escolhida for eletrônica, o retorno também será via e-mail.

Neste estudo, o tratamento dos dados foi feito pela tabulação, com auxílio de planilhas eletrônicas, assim como cálculos de porcentagem e correlação entre as variáveis.

\section{Apresentação e análise dos dados}

Nesta seção, apresentam-se a forma como foram coletados os dados e a sua respectiva análise. Para a coleta de dados, foi elaborado um questionário composto por 39 questões fechadas, de múltipla escolha, e 2 questões abertas. Para validação deste instrumento, foi realizado o pré-teste com quatro pessoas, a partir do qual foram apontadas algumas mudanças a serem feitas quanto ao entendimento das questões e das opções de resposta. Após algumas alterações, o questionário foi aplicado em empresas dos municípios citados, de diferentes ramos, que tinham em comum o fato de serem familiares e possuírem duas gerações da família trabalhando no negócio. Para identificar possíveis divergências entre as duas gerações foi solicitado que em cada empresa um membro de cada geração respondesse o questionário, obtendo-se, então, dois questionários por empresa.

Quanto à amostra, o número de 278 empresas, previamente estipulado para a aplicação do questionário, não foi atingida. $O$ fato se deve à grande quantidade de empresas que não responderam ao questionário e também devido ao foco da pesquisa necessitar de duas gerações da família ativas na empresa. Em muitos casos das empresas procuradas, não se enquadravam, por serem compostas por membros da mesma geração ou pela nova geração ser ainda muito jovem. Devido 
ao tempo estimado para a coleta, optou-se por encerrar a aplicação em 180 empresas, o que corresponde a 106 famílias atingidas, obtendo-se o número de 212 questionários.

\subsection{Tratamento dos dados}

Nesta seção, apresentam-se os principais dados levantados e selecionados, a fim de responder aos objetivos do estudo. A análise foi feita a partir do cruzamento das respostas das duas gerações, buscando evidenciar semelhanças e contradições entre os dois pontos de vista analisados e também a relação entre as diferentes perguntas do questionário.

O primeiro levantamento apresentado é quanto ao grau de escolaridade das duas gerações participantes da pesquisa. O Gráfico 1 representa a disparidade com relação a esse assunto nas diferentes gerações.

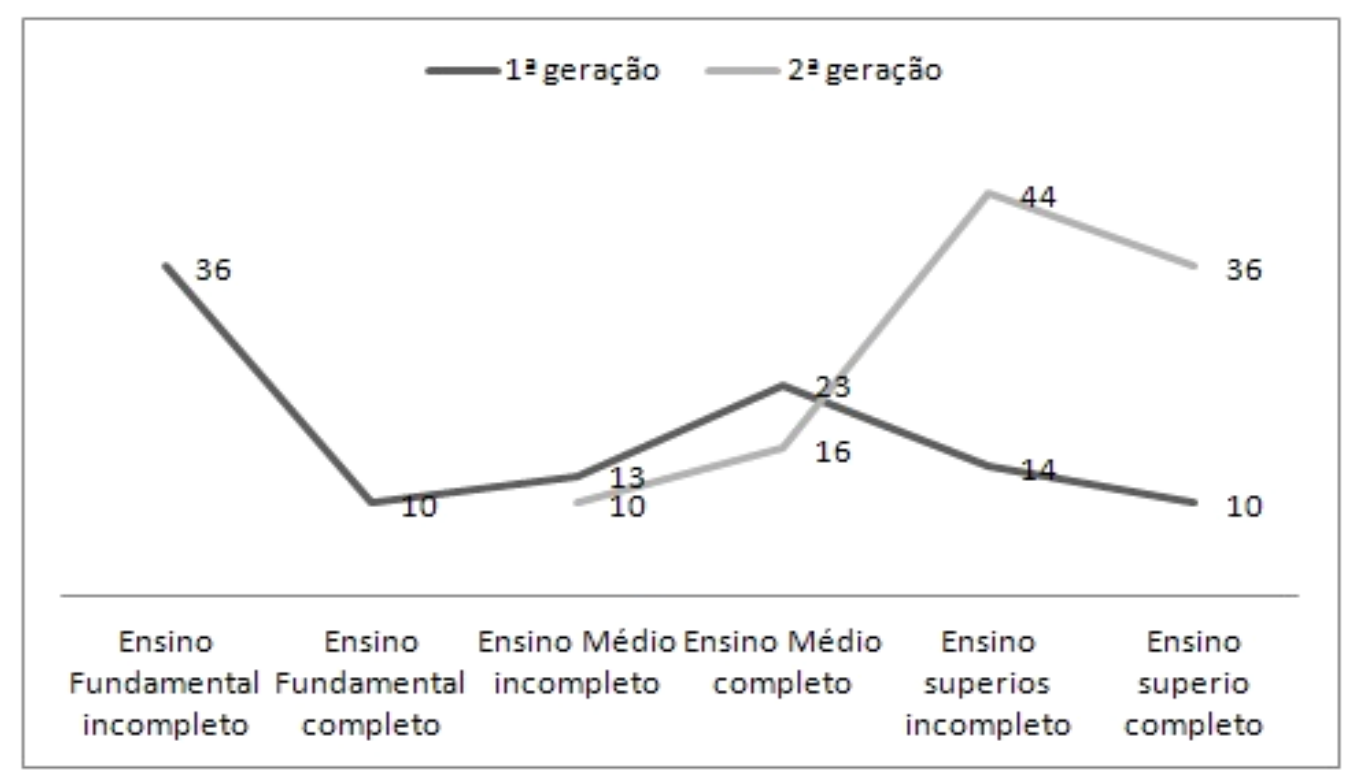

Gráfico 1 - Comparação do grau de escolaridade da primeira e segunda geração Fonte: Dados da pesquisa.

Quanto à linha que representa a primeira geração, percebe-se que a preocupação com a escolaridade não era presente no momento em que seria próprio para a formação. Com relação ao grupo da segunda geração, percebe-se que a preocupação com a qualificação é bem maior. Muito dessa disparidade é 
ocasionada pelas oportunidades que hoje são oferecidas às pessoas, como a maior facilidade de ingresso em uma universidade. Outra questão que leva a essa diferença é a necessidade que o mercado vem exigindo, tanto para a conquista de um emprego, como para que o andamento e o crescimento de uma empresa tenham maior respaldo e acompanhamento. Constata-se também que as pessoas mais jovens cada vez mais estão procurando se aperfeiçoar, buscar novos conhecimentos e novas formas de empreender, seguindo a tendência de aprimoramento e de evolução do conhecimento. Quanto aos pertencentes à primeira geração, a maioria está estagnada e não busca nenhuma forma de aperfeiçoamento, acreditando que o conhecimento adquirido até o momento é o suficiente para a sua permanência no mercado.

Outra abordagem do questionário foi quanto à especificação das funções dos familiares dentro da empresa. Com base nos apontamentos feitos pelos respondentes, verificou-se que membros de uma família, quando trabalham na empresa familiar, atuam em diferentes setores, podendo ser tanto da área da gerência, do administrativo ou da produção. Dentre todas as respostas, alguns responderam "todos fazem de tudo", e isso serve de indicativo para mostrar que, nas empresas onde os entrevistados responderam dessa forma, não existe uma estruturação e definição dos papéis de cada membro. Sendo assim, todos respondem por tudo, mas, no fundo, não existe uma designação de responsabilidades para ninguém, de forma que, ao acontecer algum problema, será mais fácil jogar a culpa para alguém do que propriamente buscar resolver a situação, sendo também um motivo gerador de conflitos entre os membros da família e da empresa.

Outras atividades apontadas relacionam-se ao andamento da empresa, como administração, gerência, controle, manutenção, criação, comando, sendo essas desenvolvidas, normalmente, pelos membros que estão à frente e no comando geral da empresa. Esses apontamentos ainda podem ser associados à gestão da empresa. No entanto, dentre todas as respostas, nenhum dos entrevistados colocou que a função de pelo menos um dos membros da família era ser gestor. Assim é possível constatar que, nas empresas familiares entrevistadas, 
não existe uma separação do planejamento e da ação, ou seja, não é incumbido a nenhum membro da família a atividade de pensar sobre o negócio e planejar ações de crescimento e melhoria para empresa, pois todos, além de cuidarem de questões administrativas e de comando, muitas vezes estão limitados à produção do produto. Isso não significa que membros da família não podem realizar atividades operacionais, mas que, em todas as empresas, independente de serem familiares ou não, é conveniente que haja uma pessoa focada no planejamento e na gestão no negócio, podendo se dedicar por inteiro a essa atividade, de forma que o resultado alcançado será mais proveitoso para a empresa e, consequentemente, para a família.

Seguindo o questionamento sobre as funções dos membros da família, foi questionado quanto à interferência de um membro na atividade de outro. A partir das respostas, foi apurado que $51 \%$ dos respondentes dos membros da primeira geração consideram que há interferência de um membro na atividade do outro. Já para $60 \%$ dos membros da segunda geração também existe essa interferência. Com base nesses dados, conclui-se que, nas empresas familiares, mesmo sendo determinada a função que cada pessoa exerce dentro da empresa, existe a intervenção por parte de outro familiar. Um fator que pode levar a essa consequência é o próprio vínculo familiar, pois, por serem parentes, sentem-se no direito de intervir no que o outro faz, mas a presença desse vínculo não exime a possibilidade de conflito entre os envolvidos: pelo contrário, as chances de existência de conflitos devido à interferência de tarefas tende a ser frequente.

Quando solicitada a informação de quem é o responsável pela gestão da empresa, 68,9\% dos entrevistados do grupo da primeira geração informaram que o responsável pela gestão da empresa é o fundador, seguido de 19,8\% por outro membro da família. Com 10,4\%, a gestão da empresa é feita em conjunto entre membros da família. Com relação ao grupo da segunda geração, $65 \%$ do total de entrevistados afirmam que a responsabilidade pela gestão da empresa é do fundador, outros $24,5 \%$ informam que a responsabilidade é de outro membro da família e 9,4\% indicam que a gestão é feita em conjunto. 
Os dados anteriores apontam que a gestão da empresa é responsabilidade de um familiar, seja ele fundador, membro da segunda geração, ou a participação conjunta dessas duas gerações. Esse fato reforça a teoria que aponta a dificuldade que a família tem em contratar alguém de fora para administrar o seu negócio, sendo até mesmo uma forma de defesa para que ninguém interfira no que é deles. Como dito anteriormente, a gestão da empresa é a forma de garantir o seu funcionamento e o seu desenvolvimento. Mesmo que seja responsabilidade de um membro da família, ele precisa estar preparado para desempenhar essa função de forma que o planejamento e as estratégias definidas venham a ter êxito, mas nada impede que a família busque alguém de fora dela para se dedicar a essa função ou também auxiliar os próprios membros da família a estruturarem essa esfera.

Uma das questões do questionário abordava a participação da família na tomada de decisão, sendo os resultados apresentados no gráfico a seguir.

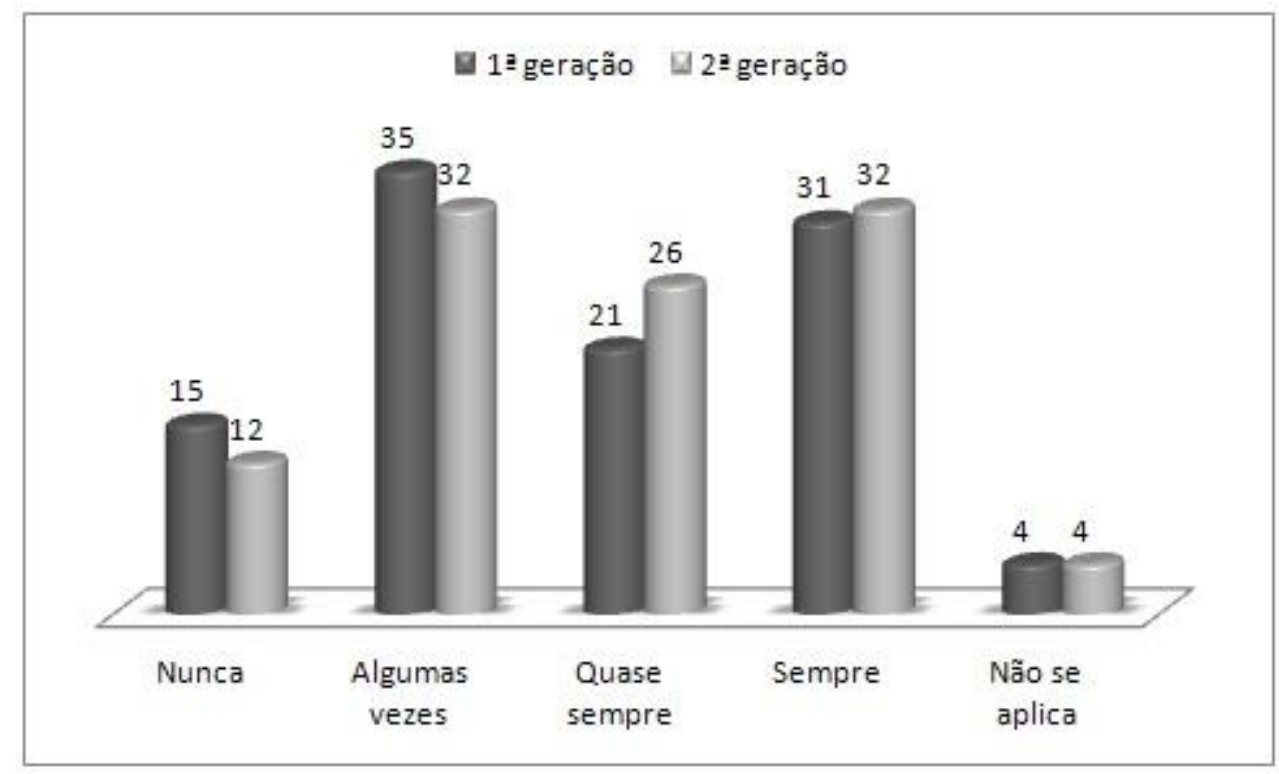

Gráfico 2 - Participação da família na tomada de decisão

Fonte: Dados da pesquisa.

Em ambos os grupos de pesquisa, e praticamente em todas as empresas, a participação da família é presente na tomada de decisão, diferenciando apenas no grau de participação, apresentada no gráfico. Quando feita uma média entre o grupo 
da primeira e da segunda geração, temos 31,6\% que responderam algumas vezes, $29,7 \%$ sempre e $22,2 \%$ que indicam que a família quase sempre participa da tomada decisão. Essa questão aponta que, mesmo se tratando de assuntos empresariais, a família está diretamente ligada e influencia a tomada de decisão. Pelos dois grupos terem praticamente a mesma percepção, subentende-se que existe um consenso sobre essa questão, e é tida como normal essa participação da família.

Quando perguntado aos respondentes sobre a participação de não membros da família na gestão da empresa, o resultado que se obteve foi que $69,8 \%$ afirmam que nunca está presente alguém que não seja da família na tomada de decisão. Isso indica que nessas empresas a gestão é tratada como função restrita da família. Esse fato pode indicar também que nessas organizações os demais funcionários não têm o direito de participar em nenhuma das etapas da gestão da empresa, existindo uma clara distinção entre os funcionários integrantes da família e os que não o são. Essa distinção pode ocasionar conflitos entre esses dois grupos, além de desmotivar os funcionários que não pertencem à família, pois não são incentivados a participar da empresa.

Com relação à sucessão, foi questionado se as empresas já passaram por esse processo e se esse foi planejado. De todos os entrevistados 54,7\% afirmam que esse processo ainda não ocorreu na empresa. Dos que afirmam que esse fato já ocorreu, 34\% do total informam que a sucessão não foi planejada.

Continuando a abordagem da sucessão, buscou-se saber se os respondentes se sentiam confortáveis com a sucessão para um membro da família. $47,2 \%$ dos respondentes do grupo da primeira geração sempre se sentem confortáveis quando pensam em transferir a responsabilidade da gestão para um membro da família. De modo geral, nesse grupo, a maioria cogita a possibilidade de que o sucessor seja da família e que isso traga tranquilidade para o antecessor. $37 \%$ dos respondentes do grupo da segunda geração também se sentem confortáveis nessas condições.

Comparando os dois grupos, o que mais chama a atenção é que quando se fala de o sucessor ser um membro da família já é um indicativo de conforto. O fato de alguns responderem que não é sempre que essa sensação é favorável pode ser 
resultado da convivência e da avaliação diária, em que o candidato a suceder o cargo, por vezes, pode tomar decisões que não esteja de acordo com o atual responsável, fazendo com que esse fique menos seguro com a transição. Mas isso não significa que as atitudes do candidato devam ser feitas pensando em agradar o gestor, pelo contrário: é com as mudanças que práticas erradas podem ser alteradas e o processo ser aperfeiçoado. De fato, uma atitude contrária pode desagradar ou até mesmo gerar algum tipo de conflito, mas quando essa decisão tiver fundamento e o resultado for positivo certamente o gestor terá mais confiança em deixar a empresa nas mãos desse familiar.

Contrapondo as informações anteriores sobre sucessão, estão os dados levantados a partir do questionamento do conforto na sucessão quando o candidato não for membro da família. 43\% dos respondentes afirmam que nunca se sentem confortáveis com essa situação, e $25 \%$ do total indicam que apenas em algumas vezes estão de acordo com a posição de favorecimento do ingresso de um sucessor de fora da família.

Isso é facilmente compreensível pelo fato de tratar-se de empresas familiares que desejam que esta tenha continuidade e que o comando do negócio permaneça nas mãos de membros da família. O fato de a empresa ter a gestão sob a responsabilidade de um profissional que não pertença à família não significa que ela vai perder o controle, mas a inclusão de um profissional da área de gestão é uma forma de aperfeiçoar o planejamento da empresa, aumentando as chances de crescimento e de continuidade, baseadas e fundamentadas em um trabalho sério e especializado.

Comparando as duas questões anteriores, percebe-se que a posição dos respondentes é oposta quando se trata de membros da família e pessoas de fora dela, indicando que o vínculo familiar fala mais alto do que a própria capacidade profissional dos indivíduos, de forma que esta constatação mais uma vez completa as afirmações de que existe interferência na gestão da empresa por esta ser familiar.

Quanto ao conflito e a sua interferência na gestão da empresa familiar, para $34,9 \%$ do grupo da primeira geração, a interferência dos conflitos na gestão e na 
condução da empresa ocorre algumas vezes, mas $52,8 \%$ do total deste grupo acreditam que o conflito atrapalha quase sempre ou em todas as vezes. Para a maioria dos membros do grupo da segunda geração, cerca de $40 \%$, acreditam que os conflitos interferem apenas algumas vezes na gestão e condução da empresa. Somando os que dizem que a interferência ocorre sempre ou quase sempre, resulta em $48 \%$ do total.

De fato, é sabido que uma das particularidades das empresas familiares é o grande número de conflitos entre os membros da família, muitas vezes ocorrido pela divergência de interesses de cada membro. Analisando os dois grupos, vê-se que $87,7 \%$ de todos os respondentes acreditam que, de alguma forma, os conflitos atrapalham a gestão da empresa. Em muitos casos, esses conflitos surgem pela mistura de questões familiares com as empresariais, ou também assuntos referentes a questões da família, quando mal resolvidos, são utilizados contra algum familiar na hora de tomar alguma decisão na empresa. O contrário é recíproco: questões empresariais podem abalar emocionalmente o vínculo familiar. Muitos dos conflitos que ocorrem entre a família e a empresa não podem ser evitados, pois são inerentes a esse tipo de empresa, mas o importante é que todos os envolvidos precisam estar dispostos a solucionar essas questões de forma que a empresa não atrapalhe a família e vice-versa, sendo um alicerce do outro e que, juntos, possam crescer e se desenvolver.

Mais uma abordagem feita foi quanto à relevância da presença da nova geração da família na empresa, e o resultado foi que $46 \%$ do total de entrevistados afirmaram que é sempre relevante a presença da nova geração. De forma geral, esse dado aponta uma das características mais marcantes de uma empresa familiar, que é a união de duas ou mais gerações em prol de uma empresa, de maneira que ela cresça junto com a família. Essa união é a compilação do velho e do novo, em que o mais antigo contribui com a experiência e o mais novo com a mudança e a renovação, buscando o desenvolvimento constante da empresa na qual estão inseridos.

Frente à presença da nova geração, foi questionado se as ideias apresentadas por ela são aplicadas na empresa. Na média das respostas, o 
resultado que se teve foi que $41,5 \%$ dos respondentes informam que as ideias da nova geração são aplicadas na empresa apenas algumas vezes, e 32\% indicam que as ideias são quase sempre aplicadas.

Dois motivos podem ser apontados como razão desses dados. Um deles é quanto à qualidade da sugestão dada pela nova geração, que logicamente precisa ser avaliada pelo responsável, para que esse verifique a viabilidade de implantação, de forma que a sugestão seja para uma mudança positiva, que irá contribuir com determinado processo. A segunda opção seria o fato de o responsável, apesar de dar liberdade e ouvir as sugestões da nova geração, seguir sua intuição e vontade, não considerando realmente o que foi the proposto. Quando o motivo for o segundo, a empresa tende a permanecer da mesma maneira que está, pois a forma que ela vem sendo conduzida não apresenta nenhuma mudança ou melhoria, sem contar que pode estar desperdiçando ótimas sugestões da nova geração. Outra consequência é quanto à sucessão que se tornará mais complicada, pois dificilmente o sucessor seguirá a forma com que a empresa foi conduzida até o momento, e conflitos de opinião entre as gerações passa a ser comuns. A empresa ainda sofrerá mais se a sucessão ocorre pela falta do atual gestor, pois o sucessor pode não estar inteirado o suficiente para continuar o trabalho e por conta disso a empresa pode acabar sendo fechada.

\subsection{Resultados}

Nesta seção, será apresentado o resumo das conclusões obtidas através da apresentação e análise dos dados. Com a aplicação do questionário a dois grupos da mesma empresa e família, foi possível verificar as diferenças e semelhanças existentes entre membros de diferentes gerações.

A primeira percepção foi com relação à divergência de respostas em diversas questões, na verdade, praticamente todas, inclusive com relação a assuntos básicos, que não envolve a opinião do entrevistado, como no caso das questões 17 e 18, nas quais o respondente precisava apontar o responsável pelo comando e gestão da empresa. Isso mostra que, em diversos temas, as empresas familiares participantes do estudo apresentam grande informalidade, em que 
questões pontuais e necessárias para o andamento não são formalizadas, ou então essas informações não são abertas para todos os envolvidos. Nesse sentido, é possível ver também que boa parte do que acontece na empresa está sob a responsabilidade do membro da empresa mais antigo e que, em muitos casos, a participação de outras gerações não ocorre.

Outra questão percebida é com relação à barreira protetora que os membros da família fazem ao seu redor, ou seja, o envolvimento de pessoas que não pertençam à família é bastante restrito, por mais que em algumas perguntas as respostas sobre essa participação tenha sido positiva. Essas restrições são ainda mais acentuadas no grupo da primeira geração, que dão a impressão de que, se for aberto espaço para o ingresso de pessoas de fora da família em funções que envolvam a gestão da empresa, ela irá fugir do seu controle. Esse é um fato que também aponta o motivo pelo qual o membro mais antigo detém para si boa parte das funções de comando e de gestão.

Foi possível verificar que várias das peculiaridades das empresas familiares descritas no referencial teórico fazem parte das empresas das cidades que participaram deste estudo, como os conflitos, a ligação entre empresa e família, a sucessão, que ainda não é tratada de forma aberta e planejada, o desejo de que a empresa continue sobre os comandos de membros da família, a grande resistência às mudanças e à participação de pessoas de fora da empresa, fatos todos que acabam interferindo diretamente na gestão e comando da empresa, sendo essas também algumas das dificuldades que esse tipo de empresa enfrenta, além das convencionais, pertinentes a qualquer tipo de empresa.

De forma geral, percebe-se que a empresa familiar é um negócio como qualquer outro, mas com detalhes próprios, que merecem bastante atenção para que o foco da empresa e da própria família não se perca. O principal deles é a conciliação entre família e empresa, o que logicamente inclui os membros dos dois grupos, pois, com o equilíbrio dos fatores próprios, a preocupação maior será conduzir a empresa baseando-se em uma gestão estruturada, que contribua para o crescimento da empresa de forma que ela permaneça de pé por várias gerações. 


\section{Considerações finais}

Ao concluir este estudo, é possível fazer algumas considerações.. Com relação às empresas familiares, de forma geral, fica claro que são de extrema importância para a economia mundial, e para as cidades foco do estudo não é diferente, devido a sua quantidade e a sua representatividade. Outro ponto bastante abordado é quanto às peculiaridades que as empresas familiares enfrentam. Essas duas questões acabam justificando o presente estudo. Apoiado nesses dois pilares, aliados à importância da gestão para as empresas, é que o problema da pesquisa foi estipulado, visto que inicialmente a abertura desse tipo empresa é motivada, normalmente, pela vontade, necessidade, oportunidade, quando a gestão acaba ficando em segundo plano.

Para tentar responder às questões levantadas, como a interferência dos conflitos familiares na gestão da empresa, como é a instrução dos membros da família, como a modernização e a profissionalização está sendo tratada pelas empresas familiares, como anda a participação da nova geração no negócio, e se existe um planejamento de sucessão que o questionário foi elaborado e aplicado a diversos representantes de empresas familiares. Com a apresentação dos resultados e de suas respectivas análises, é possível afirmar, agora, que os objetivos da pesquisa foram atingidos, e as dificuldades que as empresas familiares das duas cidades passam puderam ser levantadas de forma interessante, por poderem ser visualizados dois pontos de vista sobre a mesma questão e pelo fato de a pesquisa buscar respostas de duas gerações diferentes.

Dentre as dificuldades enfrentadas pelas empresas, cita-se a diferença na instrução das gerações. Além disso, a gestão normalmente não é estruturada, uma vez que as próprias atividades dos membros da família não são definidas. Já os conflitos ocorrem devido à interferência da relação família e empresa, assim como a interferência dos familiares nas atividades e atribuições de outro. As mudanças e a presença da nova geração nem sempre são vistas com bons olhos, e, consequentemente, as ideias propostas por esse grupo não são sempre aceitas. A presença de profissionais que não pertencem à família ainda é bastante restrita, 
principalmente para funções de gestão e comando. Por fim, a sucessão, apesar de ser uma preocupação, não possui um planejamento para a sua execução.

Outras percepções obtidas frente aos resultados são quanto ao papel da segunda geração na empresa, e que a mudança e o aperfeiçoamento dos processos e da gestão estão diretamente ligados ao empenho e à perseverança de que esse grupo necessita para que as novas ideias sejam implantadas e surtam os efeitos esperados. Uma das maneiras de convencer a geração anterior a aplicar as mudanças seria por meio da apresentação de dados concretos dos resultados que a mudança trará, permitindo uma prévia visualização do efeito da mudança. Se essas informações estiverem ligadas a fatores e ao retorno financeiro, o apoio para implantação da ideia tende a crescer.

Quanto à restrição às mudanças, é possível afirmar que a família tende a criar uma barreira protetora ao seu redor, independente da geração, o que acaba bloqueando o ingresso de pessoas não pertencentes à família, consequentemente perdendo um auxílio externo e muitas vezes profissional. Cabe ressaltar que a presença de um profissional na empresa que não pertença à família não significa que não existirão os conflitos, pois esses já estão intrínsecos na relação família/empresa. A figura desse profissional serviria como um suporte e auxílio para a condução e planejamento da empresa e solução de alguns problemas, já que outros são pertinentes aos familiares resolverem.

Ao refletir sobre a presença de pessoas que não pertencem à família, levase a pensar em outros motivos que levam ao bloqueio do ingresso desse tipo de pessoa na empresa. Um deles seria o sentimento de perda do comando e do controle do negócio, principalmente quando se trata de membros da geração mais antiga da empresa. Outro motivo seria pelo sentimento de obrigação de regulamentação e de formalização dos processos, devido à presença de uma pessoa especializada para essa função, de forma que as mudanças precisariam acontecer. Essa percepção remete ao pensamento do real desejo de melhoria da organização, ou se é preferível permanecer acomodado com a situação atual, deixando tudo como está, ocasionando dificuldades de crescimento, desenvolvimento e permanência no mercado. 
A partir dessas constatações, é possível afirmar que todos esses apontamentos refletem na gestão da empresa e, consequentemente, no desenvolvimento das empresas familiares. Mas, ao mesmo tempo, são questões que, se trabalhadas, podem ser superadas, e o fato da empresa ser familiar passa a ser um ponto positivo para o negócio e não um problema a mais para sua condução.

Um dos obstáculos enfrentados para o desenvolvimento deste estudo foi a falta de dados concretos sobre o número e informações das empresas familiares dos municípios estudados. Devido a isso, fica este estudo como uma contribuição de fonte e referência de pesquisa para estudos futuros ou até mesmo para a continuação deste mesmo.

\section{Referências}

ÁLVARES, E. (Org.). Governando a empresa familiar. Belo Horizonte: Fundação Dom Cabral, Rio de Janeiro: Qualitymark, 2003.

BERNHOEFT, R. Empresa familiar: sucessão profissionalizada ou sobrevivência comprometida. 2. ed. São Paulo: Nobel, 1991.

BEZERRA, É. As dificuldades de administrar empresas familiares. São Paulo: Rh.com.br, 7 dez. 2009. Disponível em:

<http://www.rh.com.br/Portal/Mudanca/Entrevista/6370/as-dificuldades-deadministrar-empresas-familiares.html>. Acesso em: 26 ago. 2012.

BORNHOLDT, W. Governança na empresa familiar: implementação e prática. Porto Alegre: Bookman, 2005.

BUENO, J. C. C.; FERNÁNDEZ, C. D.; SÁMCHEZ, A. V. Gestão da empresa familiar: conceitos, casos e soluções. São Paulo: Thomson, 2007.

GARCIA, V. P. Desenvolvimento das famílias empresárias. Rio de Janeiro: Qualitymark, 2001.

INSTITUTO BRASILEIRO DE GEOGRAFIA E ESTATístICA. As Micro e Pequenas Empresas Comerciais e de Serviços no Brasil. 2003. Disponível em: <http://www.ibge.gov.br/home/presidencia/noticias/11092003microempresahtml.shtm>. Acesso em: 19 ago. 2012.

LACOMBI, F. J. M. Dicionário de administração. São Paulo: Saraiva, 2004.

LODI, J. B. O fortalecimento da empresa familiar. 3. ed. São Paulo: Pioneira, 1989. 
MAXIMIANO, A. C. A. Administração para empreendedores: fundamentos da criação e da gestão de novos negócios. 2. ed. São Paulo: Pearson Prentice Hall, 2011.

MORAES, A. M. P. de. Iniciação ao estudo da administração. 2. ed. rev. São Paulo: Makron Books, 2001.

OLIVEIRA, D. de P. R. de. Empresa familiar: como fortalecer o empreendimento e otimizar o processo sucessório. São Paulo: Atlas, 1999.

PASSOS, É.; BERNHOEFT, R.; TEIXEIRA, W. Família, família, negócios à parte: como fortalecer laços e desatar nós na empresa familiar. 5. ed. São Paulo: Gente, 2006.

RIOS, M. Guia PEGN: como montar seu próprio negócio. São Paulo: Globo, 2002.

TONDO, C. (Org.). Desenvolvendo a empresa familiar e a família empresária. Porto Alegre: Sulina, 2008. 